The International Journal of Indian Psychology

ISSN 2348-5396 (e) | ISSN: 2349-3429 (p)

Volume 5, Issue 1, DIP: 18.01.067/20170501

DOI: $10.25215 / 0501.067$

http://www.ijip.in | October-December, 2017

Research Article

\title{
Relationship between Emotional Maturity and Social Competence in Young Adults
}

\author{
Prabhjeet Singh Narula $^{1 *}$
}

\section{ABSTRACT}

Background: The impact of Emotional maturity starts with the maintenance and enlistment of ability. The degree to which applicant's emotional maturity is considered in settling on top official contracting choices significantly affects a definitive achievement or disappointment of those administrators. The emotional maturity of the people doing the contracting is additionally significant for good procuring choices. Kokin Saera et al (2004) conducted a cross sectional study on "comparison of emotional maturity and social interaction in adolescents as compared to adults". In this study, 50 adults and 50 adolescents were given social adjustment inventory and emotional competency test. The study concluded high social interaction in adolescents as compared to adults however, prevalence of emotional maturity in adults was found to be high. Purpose: To find the relationship between Emotional Maturity and Social Competence among Young male and Female Adults. Material and Methods: Sample was collected from 80 adults (40 Males and 40 Females) age ranging 1825years both employed and unemployed from Delhi. The tools used for collecting data related to emotional maturity and social competence were Emotional maturity scale developed by Dr Yashvir Singh and Dr. Mahesh Bhargava and Social competence scale developed by Dr V.P. Sharma, Dr (Mrs) Prabha Shukla and Dr (Mrs) Kiran Shukla. Result and Conclusion: On a average, females were found to be highly emotionally mature as compared to the males at both the significance level of 0.05 and 0.1 . Moreover, there was no difference in social competence level of working and non working adults as well as social competence level was found to be not dependent on gender.

\section{Keywords: Emotional Maturity, Social Competence, Young Adults}

Increasing chronological age does not necessarily signify growth in emotional maturity, i.e. as you get older, you don't get more emotionally mature. Some adults might have never matured emotionally while some might be very mature emotionally.

\footnotetext{
${ }^{1}$ Research Scholar, OPJS University, Churu, Rajasthan, India *Responding Author

Received: August 26, 2017; Revision Received: November 26, 2017; Accepted: December 05, 2017 (C) 2017 Narula P S; licensee IJIP. This is an Open Access Research distributed under the terms of the Creative Commons Attribution License (www.creativecommons.org/licenses/by/2.0), which permits unrestricted use, distribution, and reproduction in any Medium, provided the original work is properly cited.
} 


\section{Relationship between Emotional Maturity and Social Competence in Young Adults}

Controlling your emotions does not signify emotional maturity. Emotional maturity is when you do not express reflex feelings by having a good control over your behaviour since emotional maturity is accountable for actions as well as words.

Mental health development goes consecutively with emotional maturity and it does not mean that same situation or an idea will make every person react or feel in the same way about it.

Emotionally mature people never look for or waste time in making excuses and make sure that they accept the responsibility of their behaviour/ actions, although there might be some situations wherein they might act in an immature way.

Moreover, such people do not try to blame others even in difficult situations and feel that it is their responsibility to overcome such a state.

\section{Theories Of Emotion}

\section{- James-Lange theory}

William James (1884) and Carl Lange (1887) originated the theory of emotions with the same idea and around the same time, popularly known as the James-Lange theory. According to their theory, an event leads to a bodily response initiated by the emotion and not by the perception of an event. This means that, when a bodily response (e.g., increased breathing, increased heart beat, sweaty hands) occurs, it is the response of an emotion. For example, my heart beat increases looking at a ferocious dog barking at me and perceiving my increased heart rate, my brain figures out that I am experiencing fear.

\section{- Cannon-Bard Theory}

The theory began with the work of Walter Cannon with contemplation that the James-Lange theory was flawed for a number of reasons (Cannon, 1927). He observed through his experiments in certain animals like cats that even after the brain was cut off from the information about bodily responses, the emotions still occurred. Moreover, as per his observations, many different emotions were resultant of the same bodily responses. For example, when one is angry, the heart beat increases, however it may also signify that one is excited in a positive way. This means that our brain cannot just rely on our bodily responses to know which emotion we are experiencing (i.e., there must be something else that tells us whether we are angry or excited). Philip Bard in consensus with Cannon continued examining the emotions in the brain. Through their research, Cannon and Bard concluded that experience of an emotion independent of input from the body and the way it responds. Both the bodily response as well as experience of the emotion occurs at the same time independently of each other.

\section{- Schachter-Singer theory}

The Schachter-Singer theory, concluded that experiencing an emotion requires considering the particular situation the person is in at the moment along with the bodily response and an interpretation of the bodily response (Schachter \& Singer, 1962). For eg, if an alligator is chasing me and my heart beat increases, it may be interpreted as fear. On the other hand, if I am looking at the person I am in love with and my heart beat increases, it may be interpreted 


\section{Relationship between Emotional Maturity and Social Competence in Young Adults}

as excitement. Thus, I might experience very different emotions depending on the type of situation I am in, even though the bodily response is the same.

The impact of Emotional maturity starts with the maintenance and enlistment of ability. The degree to which applicant's emotional maturity is considered in settling on top official contracting choices significantly affects a definitive achievement or disappointment of those administrators. The emotional maturity of the people doing the contracting is additionally significant for good procuring choices. Emotional maturity additionally influences the improvement of ability. Be that as it may, not all connections are similarly powerful in doing as such. The emotional maturity of the guide, manager, or companion will impact the capability of an association with that individual for helping hierarchical individuals create and utilize the ability that is urgent for authoritative viability. Martin Seligman (1991) has developed a construct that he calls learned optimism. It alludes to the causal attributions individuals make when stood up to with disappointment or misfortunes. Positive thinkers tend to make particular, brief, outside causal attributions while doubters make worldwide, changeless, inner attributions. Emotional maturity has as much to do with knowing when and how to express feeling as it does with controlling it.

\section{General characteristics of Emotional immaturity.}

\section{A. Signs}

- $\quad$ Being grouchy and discouraged excessively of the time

- $\quad$ Crying, sulking, losing temper and shouting over inconsequential issues.

- $\quad$ Being late for arrangements or enabling joys to hinder school assignments

\section{B. Other responsibilities:}

- $\quad$ Staying up past the point of no return during the evening when you ought to be getting your rest - then dozing in past the point of no return for classes or work.

- $\quad$ Staying in quaint little inn in debilitated when you feel somewhat worn out or down, as opposed to training yourself and putting your duties first.

- Getting distraught on the off chance that you aren't the focal point of consideration and the most well known young lady around. Or, on the other hand, getting bothered and rude when you don't get your direction.

- $\quad$ Being requesting of other individuals and feeling that they should take into account your wants and needs first.

- $\quad$ Buying on drive - neglecting to consider the cost, or whether you have the assets.

- $\quad$ Failing to state "NO" to yourself — offering in to your wants and needs without limitation — dismissing the outcomes.

- $\quad$ Failing to reason out a circumstance or issue from start to finish before settling on a choice - acting first and thinking later.

- $\quad$ Being effectively impacted by others, rather than utilizing your psyche and settling on your own choices.

- $\quad$ Daydreaming - squandering your chance in a universe of imagination and pretend as opposed to speculation helpfully. 


\section{Relationship between Emotional Maturity and Social Competence in Young Adults}

- $\quad$ Reacting candidly and going to pieces in a crisis. Neglecting to gather your minds and act with a reasonable intuition head after the underlying blow has passed.

- $\quad$ Finding deficiency with everything and everyone, rather than endeavouring to coexist with individuals. At the end of the day, being by and large negative and basic toward life.

- $\quad$ Using the reason that since you're a lady and along these lines more passionate (particularly at specific circumstances of the month), you don't need to keep your feelings close by.

- $\quad$ Failing to assume the fault or being excessively persistent, making it impossible to let it be known when you are incorrect.

- $\quad$ Feeling insufficient and effortlessly disheartened — especially while partner with peers who are confident, multitalented and effective.

C. Other General Manifestations:

a. Modesty - introvert sort

b. $\quad$ Frightful of making new strides

c. Reckless

d. Indulgent

e. Cold-hearted and rude

f. Whimpers, gripes and cries effectively

g. Excessively worried about your wellbeing

h. Ill humoured, variable, insecure

I. Effortlessly irritated

j. Blaming

k. Aggressive - win or else - dependably must be first

l. Pugnacious and bigoted

m. $\quad$ Restless - everything must be "presently" — never later

n. Mocking and critical

o. Unfit to be not kidding and reasonable

p. Muddled

q. Unfit to focus

r. Reckless and undependable

\section{Emotional Maturity and Emotional Immaturity}

- $\quad$ The distinction lies in whether you let this vitality (emotion) lead you to your own heart and the heart of others, or whether you, through cautious idea, put it to utilize productively

- $\quad$ One cannot stop his/her emotions; however one can control and direct it into constructive channels.

\section{Controlling Emotion}

- $\quad$ Realize there are negative and positive approaches to respond to a motivation that comes into your psyche.

(C) The International Journal of Indian Psychology, ISSN 2348-5396 (e) | ISSN: 2349-3429 (p) | 59 


\section{Relationship between Emotional Maturity and Social Competence in Young Adults}

- $\quad$ Understand that you have been modified from early stages to respond the way you by and by do.

- $\quad$ Realize, further, you can build up the capacity to pick the way you need to respond, instead of enabling it to be programmed. As such, you can reinvent your conduct

\section{Negative Responses or Emotional Immaturity}

There are basically three factors that contribute to emotional immaturity.

\section{Conditioning}

This includes how you were dealt with as a young lady, and also what was anticipated from you. On the off chance that you were dealt with as a delicate, meek doll, instead of as a tyke, and that sort of conduct was fortified with endorsement, either verbal or nonverbal, you presumably conveyed this example into adulthood. As a female, you without a doubt were required to cry effortlessly, frown, and think externally and egotistically. You likewise figured out how to tell "white lies" to control your folks, and men. This foundation most likely added to your present make-up as a grown-up.

\section{Modeling}

Kids are imitators. Grown-ups are your mirror, particularly your folks or parent-figures. So whatever the model of the individual you related to as a kid - your mom, teacher, Hollywood star, and so forth, you will somehow end up noticeably like that individual.

\section{Cognitive Development}

This is the procedure by which you verified that specific conduct was or was not further bolstering your good fortune. Crying, sulking or having fits to get your own specific manner, turned into a long lasting manipulative gadget. It's called "water control" or "the noiseless treatment." These are negative strategies youthful ladies have figured out how to use to get their coveted outcomes.

Some of the characteristics of the person who has achieved true adulthood are suggested here: He acknowledges feedback thankfully, being genuinely happy for a chance to make strides.

- $\quad$ He does not enjoy self indulgence. He has started to feel the laws of remuneration working in all life.

- He does not expect uncommon thought from anybody.

- $\quad$ He remains calm.

- $\quad$ He meets crises with balance.

- He is a decent washout. He can continue thrashing and dissatisfaction without whimpering or grumbling.

- $\quad$ He does not stress over things he can't offer assistance.

- $\quad$ He is not given to gloating or "flaunting" in socially unsuitable ways. 


\section{Relationship between Emotional Maturity and Social Competence in Young Adults}

- $\quad$ He is sincerely happy when others appreciate achievement or favorable luck. He has outgrown envy and desire.

- $\quad$ He is sufficiently receptive to listen attentively to the assessments of others.

- $\quad$ He is not an endless "blame discoverer."

- $\quad$ He designs things ahead of time as opposed to trusting to the motivation existing apart from everything else

\section{LITERATURE REVIEW}

Voeller, studied the social competence and stated that there are three clusters of problem behaviors that lead to the impairment of social competence. Voeller clusters include: (1) an aggressive and hostile group, (2) a perceptual deficits subgroup, and (3) a group with difficulties in self-regulation.

Children with aggressive and hostile practices are those whose carrying on practices adversely impacts their capacity to frame connections, and manage relational associations. Aggressive and hostile kids have a tendency to have lacks in social data handling, and utilize unseemly social critical thinking methodologies to social circumstances. They additionally tend to look for fewer certainties in a social circumstance and give careful consideration to the forceful social connections exhibited in a communication.

Children with perceptual deficits have difficulty reading social cues, facial expressions and body gestures and do not perceive the environment appropriately and interpret interpersonal interactions inaccurately. Kokin Saera, Mihot Arsha Lim, Michael Lamb, Aldus Hoffmann (2004) conducted a cross sectional study on "comparison of emotional maturity and social interaction in adolescents as compared to adults”. In this study, 50 adults and 50 adolescents were given social adjustment inventory and emotional competency test. The study concluded high social interaction in adolescents as compared to adults however, prevalence of emotional maturity in adults was found to be high.

Purnima Shrivastava, (2004) conducted a study "evaluation of social maturity in males and females". 80 males and 80 females were considered for the study and were taken for a trip outside India. They were made to visit in a hospitality management, hospital setup and a corporate setup and were introduced to the different situations faced by these different institutions. Then they were evaluated on how they would deal with such situations. The study concluded emotional maturity being at high prevalent rate in females than males while social maturity being at high prevalent rate in males as compared to females.

In comparison to adolescents, young adults reported significantly greater use of optimism (a component of emotional maturity) as a mood regulation strategy as evaluated by Chapman and Hayslip (2006) in a cross sectional analysis with an aim to measure emotional maturity in young adulthood. In this study, differentiation of the construct of emotional maturity was investigated in adolescents and young adults. 


\section{Relationship between Emotional Maturity and Social Competence in Young Adults}

In comparison to men, women scored significantly higher in emotional intelligence as revealed by study by Mayer and Warner (2004) among 330 college students. Lower emotional intelligence in males shows principally the inability to use emotion to facilitate thought and to perceive emotions and thus was associated with negative outcomes such as and poor relations with friends, drug and alcohol use and deviant behaviour.

\section{METHODOLOGY}

\section{Objectives of the Study}

1. To find the relationship between Social Competence and Emotional Maturity in working and non working young adults.

2. To study the level of emotional maturity among Young male and Female Adults.

3. To study the level of competency in society among Young male and Female Adults.

4. To find the relationship between Emotional Maturity and Social Competence among Young male and Female Adults.

\section{Hypotheses}

1. Males are not as much emotionally mature as females.

2. Working adults have comparatively more social competence than non working young adults.

3. Females have less social competence than males.

\section{Locale of the Study}

The Present study was conducted in Delhi.

\section{Sample}

Sample was collected from 80 adults (40 Males and 40 Females) age ranging 18-25years both employed and unemployed.

\section{Tools intended to use}

1. Emotional maturity scale developed by Dr Yashvir Singh and Dr. Mahesh Bhargava

The scale comprises of 48 items under the 5 categories:

- Emotional stability

- Emotional progression

- Social adjustment

- Personality integration

- Independence

2. Social competence scale developed by Dr V.P. Sharma, Dr (Mrs) Prabha Shukla and Dr (Mrs) Kiran Shukla consists of 50 items divided under 18 factors of social competence which are:

- $\quad$ Social Sensitivity

- $\quad$ Social Maturity

- $\quad$ Social Skills

- $\quad$ Social Relations

- $\quad$ Social Commitment

- $\quad$ Social Appreciation Ability 


\section{Relationship between Emotional Maturity and Social Competence in Young Adults}

- $\quad$ Socio Emotional Integrity

- $\quad$ Social Involvement

- $\quad$ Social Respectability

- $\quad$ Social Leadership

- $\quad$ Social Cooperation And Compliance

- $\quad$ Social Acceptability

- $\quad$ Social Tolerance

- Social Competition

- $\quad$ Social Authority

- $\quad$ Adult Resource Exploitability

- $\quad$ Social Participation

- $\quad$ Pro-Social Attitude

\section{Procedure}

- $\quad$ The subjects were well informed about the study and all there queries were resolved

- $\quad$ The subjects were made comfortable and were given the necessary instructions

- After collecting the data, the scoring was done using the manual and then the conclusions were drawn

\section{ANALYSIS OF RESULTS}

Figure 1: Represents Level of emotional maturity in males and females.

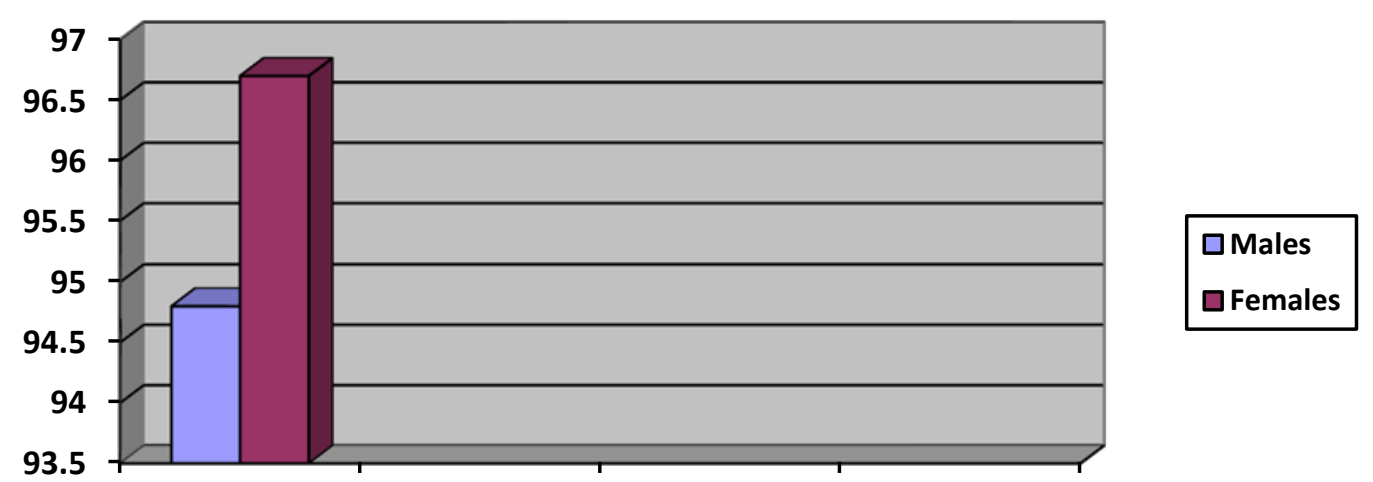

Avg Score

Figure 2, Showing Scores of SOCIAL COMPETENCE in employed male and female adults and in unemployed male and female adults

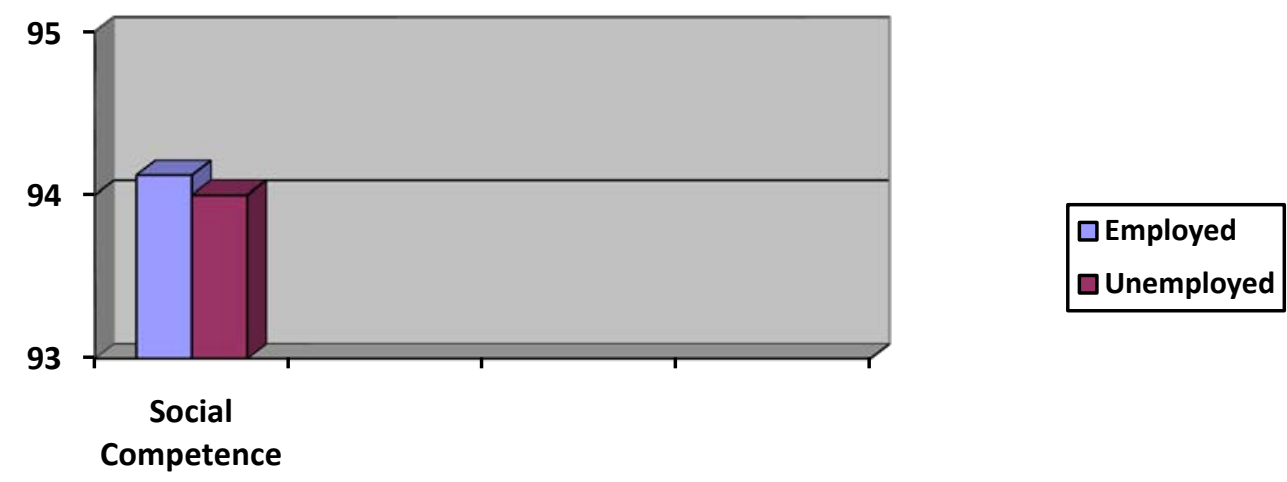

(C) The International Journal of Indian Psychology, ISSN 2348-5396 (e)| ISSN: 2349-3429 (p) | 63 
Figure 3: Represents Level of social competence in males and females.

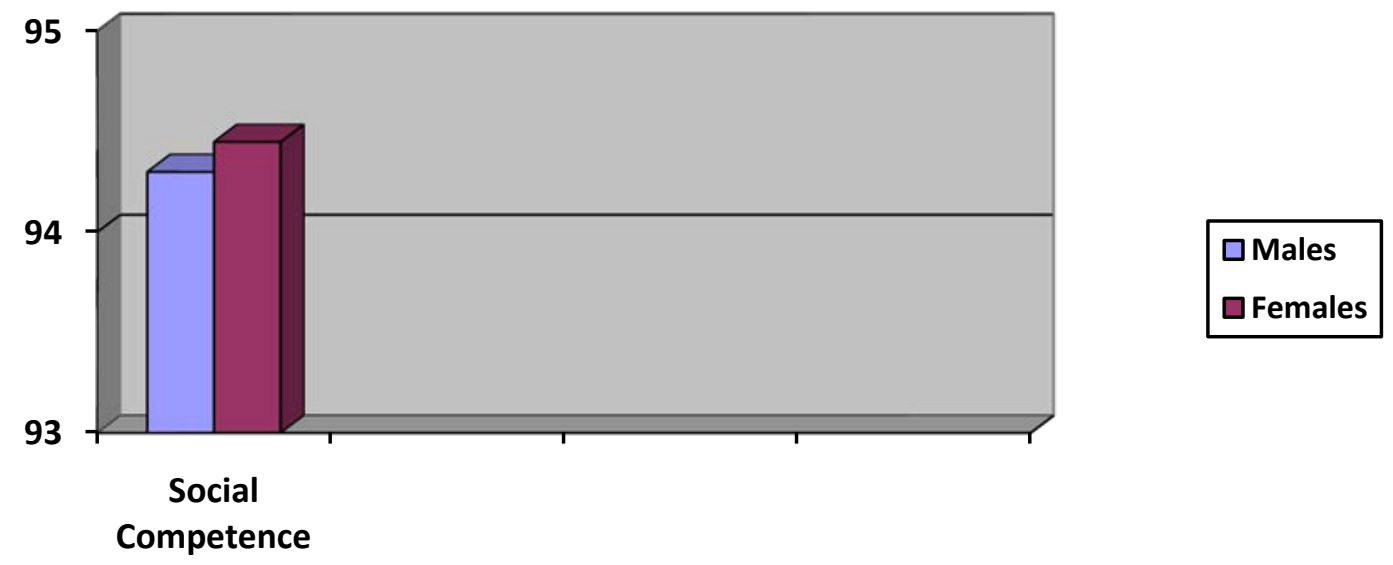

\section{DISCUSSION}

For the study titled "Relationship between Emotional Maturity and Social Competence in young adults", a sample of 80 young adults, 40 males and 40 females, were taken into consideration from New Delhi. The Independent Variables were emotional maturity, males and females, employed and unemployed while the Dependent Variable being social competence. The Psychological tool used were: (i) Emotional Maturity Scale by Dr Yashvir Singh and Dr Mahesh Bhargava and (ii) Social Competence Scale by Dr V.P. Sharma, Dr (Mrs) Prabha Shukla and Dr (mrs) Kiran Shukla

The analysis of the data collected revealed that on average females are more emotionally mature than males and there was a significant difference at both the levels ie 0.05 level as well as 0.01 level. However, there is no significant difference in social competence of employed and unemployed adults. This implies that there is no relation between specific working or non working environment on social competence. Moreover, there is no significant difference in social competence with regard to males and females. This implies that there are no specific criteria that males are more competent than female.

The findings are somewhat in consensus with the previous research already conducted for "evaluation of social maturity in males and females" Purnima shrivastava (2004which also concluded high prevalent rate of social maturity in males as compared to females and high prevalent rate of emotional maturity in females than males.

\section{CONCLUSION}

The title of the present study is "Relationship between Emotional Maturity and Social Competence In Young Adults". The sample for the research was taken from Delhi with a sample size of 80 adults, age ranging 18-25 years - 40 Males and 40 Females.

\section{The findings of the present study can be epitomized as under -}

- $\quad$ On average, females are more emotionally mature than males and the emotional maturity was seen significant at both 0.05 and 0.01

- There is no relation of working or non working environment on social competence

(C) The International Journal of Indian Psychology, ISSN 2348-5396 (e)| ISSN: 2349-3429 (p) | 64 


\section{Relationship between Emotional Maturity and Social Competence in Young Adults}

- $\quad$ The social competence does not have a relationship with gender

\section{RECOMMENDATIONS FOR FURTHER RESEARCH WORK}

1. Research may be extended to larger geographic area as well as other sections of society.

2. Other attributes that may be having an impact on employed person as compared to unemployed person should be taken in to consideration.

3. Other correlates of social competence such as Personality, Childhood Experiences, Marital Status, Behaviour Pattern can also be studied.

4. Parent- child relationship and emotional maturity amongst them can also be studied.

5. Impact of urban living and rural living can also be compared to see the impact of emotional maturity and other psychological variables.

\section{Acknowledgments}

The author appreciates all those who participated in the study and helped to facilitate the research process.

Conflict of Interests: The author declared no conflict of interests.

\section{REFERENCES}

Bandura, A. (1977): Social Learning Theory. Englewood Cliffs, N.J: Prentice-Hall, p.22

Benard, H.W. (1965). Psychology of Learning and Teaching. New York: McGraw Hill Book Co.

Bhargava, M. (2006). Modern Psychological Testing and Measurement (Hindi).Agra: H.P. Bhargava Book House.

Guilford, J.P. (1954): Psychometric Methods (4 ${ }^{\text {th }}$ ed.)

Goldfriend, M.R. And D'Zurilla, T.J. (1963): A behavioural analytical model for assessing competence. Volume1, New York, academic press.

Harper, A.E., Dassgupta, B. and Sandal, S.P. (1965): Item Analysis Chart and Introduction, Mansayan, Delhi.

Levinson, D. J. (1986): A conception of adult development, American Psychologist, vol. 41, pp. 3-13.

Mohsin, S.M. (1960). A measure of Emotional Maturity. Psychological Studies, 78-83.

Rao, Nalini (1974): Social Maturity Scale, National Psychology Corporation, Agra.

Seoul, L.J. (1951). Emotional Maturity, The development and dynamics of personality, London: j.b. Lippincott.

Shaver, P. (1986). Being emotionally stable journal : Perspectives from attachment theory. As cited in Sears

Sinha, A.K.P. and Singh, R.P.(2004). Adjustment inventory for college students (AICS). Agra: National Psychological corporation.

White, R.W.(1960): Motivation reconsidered: The Concept Of Psychological Review

Zingler, E.(1972): Competency: Social competence and its development International Encyclopaedia of Psychology, Psychiatry, Psychoanalysis and Neurology, no.3, p. 287.

How to cite this article: Narula P S (2017). Relationship between Emotional Maturity and Social Competence in Young Adults. International Journal of Indian Psychology, Vol. 5, (1), DIP: 18.01.067/20170501, DOI: 10.25215/0501.067 